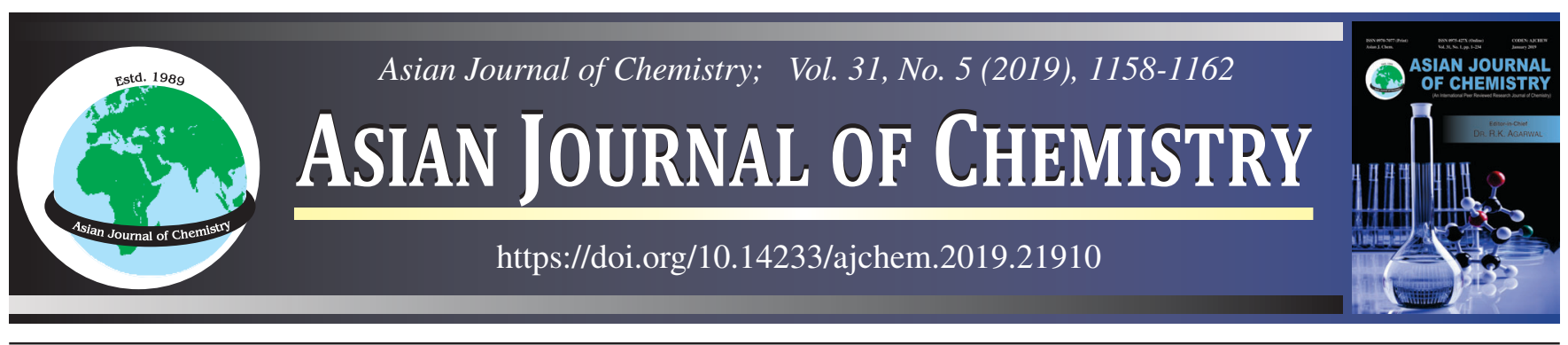

\title{
Synthesis and Investigations of Structural, Optical and AC Conductivity Properties of $\mathrm{PANI} / \mathrm{CeO}_{2}$ Nanocomposites
}

\author{
R. ANitha ${ }^{1,2, \bullet}$, E. Kumar ${ }^{3, * \bullet}$ and S.C. Vella DuraI ${ }^{4, \bullet}$
}

${ }^{1}$ Department of Physics, Bharathiar University, Coimbatore-641046, India

${ }^{2}$ Department of Physics, Sri S. Ramasamy Naidu Memorial College, Sattur, Virudhunagar-626203, India

${ }^{3}$ Department of Physics, School of Science, Tamil Nadu Open University, Chennai-600015, India

${ }^{4}$ Department of Physics, J.P. College of Engineering, Ayikudi, Tenkasi-627852, India

*Corresponding author: E-mail : kumarnano@gmail.com

Received: 31 December 2018;

Accepted: 1 February 2019;

Published online: 28 March 2019;

AJC-19348

\begin{abstract}
This paper explains the details on the preparation of polyaniline/ $\mathrm{CeO}_{2}(10 \mathrm{wt} \%)$ nanocomposites using the method of $i n$ situ polymerization. The formation of PANI/ $\mathrm{CeO}_{2}$ nanocomposites were proposed via oxidation of aniline and reduction of $\mathrm{CeO}_{2}$, respectively. The effect of $\mathrm{CeO}_{2}$ concentration on $\mathrm{AC}$ conductivity, morphological, optical and structural properties of the prepared $\mathrm{PANI}^{\mathrm{C}} \mathrm{CeO}{ }_{2}$ nanocomposites material were examined. The structural studies show the presence of $\mathrm{CeO}_{2}$ nanoparticles were occurred in PANI of nanocomposites. The average grain size of $\mathrm{PANI} / \mathrm{CeO}_{2}$ nanocomposites varied with increasing and decreasing concentration due to the process of nucleation during the polymerization. The average particle grain sizes were measured from HRTEM. The morphology analysis was carried out from SEM. The UV absorption spectrum showed that the absorption peak of $\mathrm{CeO}_{2}$ nanoparticle at $341 \mathrm{~nm}$, shifted to lower wavelength side, the nanocomposite absorption peaks at about 324,368 and $858 \mathrm{~nm}$ was confirmed by the formation of $\mathrm{PANI} / \mathrm{CeO}_{2}$ nanocomposites. The electronic structure of the band gap of the nanocomposite materials were calculated using ultraviolet visible absorption spectrum. The band gap energy of nanocomposite is $3.36 \mathrm{eV}$. The FTIR spectrum clearly showed the strong presence of $\mathrm{CeO}_{2}$ nanoparticles in PANI chain. The $\mathrm{AC}$ conductivity varied with varying the temperature and depends on the concentration due to the formation of $\mathrm{PANI}^{\mathrm{C}} \mathrm{CeO}_{2}$ nanocomposite.
\end{abstract}

Keywords: PANI, Nanocomposites, Spectrum, Temperature, Polymer.

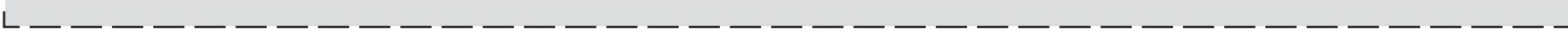

\section{INTRODUCTION}

The polymer composite material has given the important responsibility of new materials [1]. When it is made a composite and mixed to nano-size materials, polymer composite has applications of one or more dimensional materials and amorphous materials [2]. In the important development of nanosized materials have a way of increasing the quality of structure and strength of the prepared polymer nanocomposite materials. In this century, nanotechnology is a quality promising field of energy storage and biotechnology systems [3]. In the basic idea of nanotechnology is in controlled prepared nanosize particle and polymer nanocomposites on the size of particles 1 to $100 \mathrm{~nm}$ [4]. This nanotechnology effort will help to raise the fields of materials science, physics and integrated chemistry [5]. All type of materials like crystalline and amorphous materials was got the polymer nanocomposite materials from the different type of preparation. These new materials of polymer nanocomposites are helping to increase the quality of societal advantages in the world. So we were interested to prepare the polymer nanocomposites materials in the combination of conducting polymer and metal oxide. Conducting polymers are conjugated chain of organic compounds; it shows good conductivity similar to good conductivity metal because of the presence of large number of charge carrier of extended $\pi$ electrons [6]. The backbone of the polymer chain has charge mobility, which allows conducting polymer [7]. Their conductivity behaviour is compatible with normal conductors but conducting polymer has large advantages [8], like as being flexibility, light weight and very less amount. These conducting polymers have various applications of mobile phone, LED, batteries, solar cells, many microelectronic devices and sensors

This is an open access journal, and articles are distributed under the terms of the Creative Commons Attribution-NonCommercial-ShareAlike 4.0 (CC BY-NC-SA 4.0) International License which allows readers to freely read, download, copy, distribute, print, search, or link to the full texts of its articles and to use them for any other lawful non-commercial purpose as long as the original source is duly acknowledged. 
[9]. Among the conducting polymer families, polyaniline (PANI) has been of peculiar characteristics. It is most controllable electrical conductivity, nice redox properties, good conductivity, easy polymerization, chemical stability and low cost monomer. PANI combined with pure inorganic nanoparticles like as $\mathrm{MnO}_{2}, \mathrm{SnO}_{2}$ and $\mathrm{TiO}_{2}$ to form PANI/metal oxide nanocomposite to improve electrical, chemical and physical properties. This type of nanocomposite has many advantages, can have good potential applications in latest devices. The combining properties of nanocomposites have improved the optical and dielectric properties [10]. Metal oxide could act as conductive junctions, between the PANI chains that resulted in an increase of the electrical conductivity of the nanocomposites. The among metal oxide nanoparticles used, cerium oxide $\left(\mathrm{CeO}_{2}\right)$ nanoparticle are very nice in modern materials. Due to special magnetic, optical and electronic properties. $\mathrm{CeO}_{2}$ has many applications in capacitors, microelectronics, electrode materials, solar cells and biomedical fields [11]. The synthesis of $\mathrm{CeO}_{2}$ nanoparticles embedded in PANI using chemical, electrochemical and in situ polymerization methods. In this research article reported that, the $\mathrm{PANI} / \mathrm{CeO}_{2}$ nanocomposites (10 wt \%) are synthesized with using of chemical agent of ammonium per sulphate in situ polymerization method. PANI/ $\mathrm{CeO}_{2}$ nanocomposites material could have nice behaviour between electrical properties of PANI and metal oxide for new devices.

\section{EXPERIMENTAL}

The two moralities $\mathrm{HCl}$, ammonium persulphate, prepared $\mathrm{CeO}_{2}$ nanoparticles and aniline were used to prepare $10 \mathrm{wt} \%$ of nanocomposites in situ polymerization technique.

General procedure: In a typical preparation $\mathrm{PANI} / \mathrm{CeO}_{2}$ nanocomposites were synthesized in situ polymerization methods as follows: The $4.5 \mathrm{~mL}$ of aniline and $70 \mathrm{~mL}$ of $\mathrm{HCl}$ in $2 \mathrm{M}$ are mixed and stirred at $60^{\circ} \mathrm{C}$. In this prepared solution, $0.9 \mathrm{~g}(10 \mathrm{wt} \%)$ of prepared $\mathrm{CeO}_{2}$ nanoparticles was added and stirred continuously for $3 \mathrm{~h}$. During the stirring, prepared ammonium persulphate solution was added drop-wise into the solution. The prepared solution was filtered and washed by de-ionized water. The finally green colour precipitate was dried for room temperature for 3 days.

Detection method: The powder XRD pattern of the nanocomposites sample was recorded as PAN analytical model diffractometer $\left(\mathrm{K}_{\alpha}=1.54056 \AA\right.$ at $\left.35 \mathrm{kV}, 10 \mathrm{~mA}\right)$. The sample was scanned at the angle of $10^{\circ}$ to $80^{\circ}(2 \theta)$. The high resolution transmission electron microscopy (HRTEM) image was carried out at JOEL JEM 2100. The scanning electron microscope (SEM) images were recorded at Hitachi SEM. The optical spectrum of FTIR was carried out using 8400S Shimadzu spectrometer at the range wave number $4000-400 \mathrm{~cm}^{-1}$. Another optical spectrum of UV was recorded in the wavelength range of 190-1100 nm. AC conductivity analysis was carried out using a Zahnner zennium IM meter in the frequency range of $10 \mu \mathrm{Hz}$ to $8 \mathrm{MHz}$ at various temperatures.

\section{RESULTS AND DISCUSSION}

X-ray diffraction studies: Fig. 1 shows that X-ray diffraction pattern of as synthesized nanocomposite (10 wt \%) materials. The prepared $\mathrm{PANI} / \mathrm{CeO}_{2}$ nanocomposites has been compared to the result with XRD pattern of the samples of pure $\mathrm{CeO}_{2}$ and pure PANI. Pure $\mathrm{CeO}_{2}$ is a nano-crystalline nature [12] and conducting polymer PANI is also nanocrystalline nature materials [13]. From Fig. 1 is clear that peaks show that the prepared nanocomposite materials are crystalline in nature. It was clearly observed that the changes of peak intensities compared to the pure sample of $\mathrm{CeO}_{2}$ and PANI nanoparticles. This indicates the peaks of XRD pattern and results intercalated morphology of pure sample, the $\mathrm{CeO}_{2}$ nanoparticles intercalated within the polymer matrix due to the penetration of pure nanoparticles, have in dispersion of the $\mathrm{CeO}_{2}$ nanoparticles with in the polymer matrix. The particle grain size was calculated using FWHM, the formula is

$$
\mathrm{d}=0.9 \lambda / \beta \cos \theta
$$

where $d$ is the crystalline size in $\mathrm{nm}, \lambda$ is the wavelength of $\mathrm{X}$-ray in $\AA, \beta$ is the FWHM and $\theta$ is the angle of diffraction in degrees. The particle grain size of the nanocomposites are observed and is varied from which compared to the pure materials. Particle grain size of maximum number of nanoparticles is around $16.5 \mathrm{~nm}$.

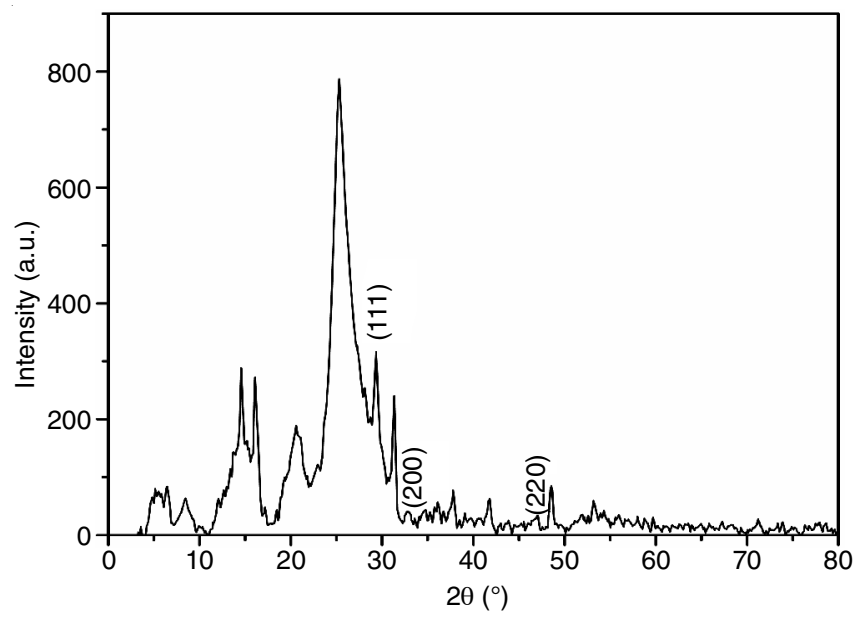

Fig. 1. XRD pattern of $\mathrm{PANI} / \mathrm{CeO}_{2}$ nanocomposites

SEM and HRTEM studies: Fig. $2 \mathrm{a}$ and $2 \mathrm{~b}$ show images of SEM and HRTEM. From images it is observed to be spherical with small agglomeration. Fig. $2 \mathrm{a}$ and $2 \mathrm{~b}$ clearly indicate that the pure nanoparticles PANI and $\mathrm{CeO}_{2}$ penetration on the matrix of polyaniline, was confirmed on the formation of nanocomposites. HRTEM image shows agglomerated cluster of $\mathrm{CeO}_{2}$, it is reduced that the making nanocomposites [14]. The polymer chains have been occurred nanoparticles in the compositions of $\mathrm{PANI} / \mathrm{CeO}_{2}$ nanocomposites. From the image shows that the nanocomposites particles were nearly spherical shape, it is possible to confirm of various crystallographic lattice plane of different atomic density. These images exhibit that the range of particles from 10 to $20 \mathrm{~nm}$. It will give proof for the confirmation of supra-aggregates as found in the image of HRTEM and supra-aggregates are nearly stable from the nanoncomposites suspension [15]. From some images could occurred in very smaller particles size of 5-10 nm, are combined together to grown to irregular shape of nanocomposites within the size of single particles. Since, nanocomposites 


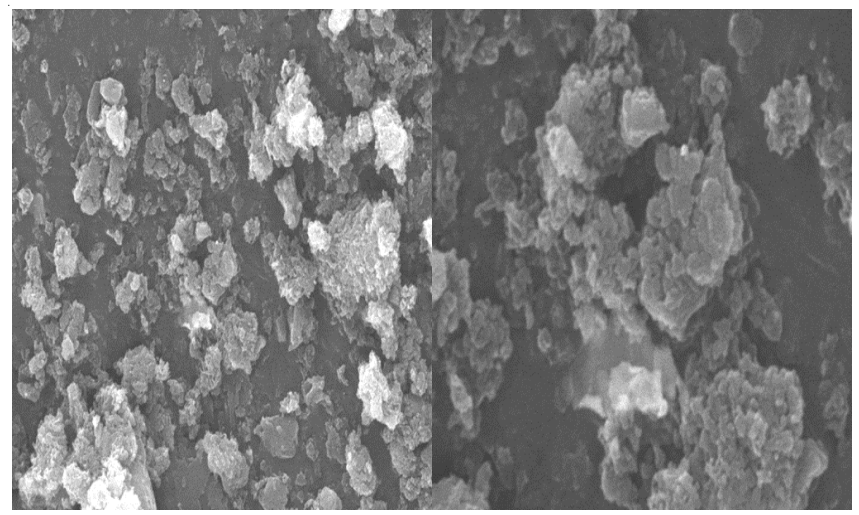

Fig. 2a. SEM image of $\mathrm{PANI} / \mathrm{CeO}_{2}$ nanocomposites

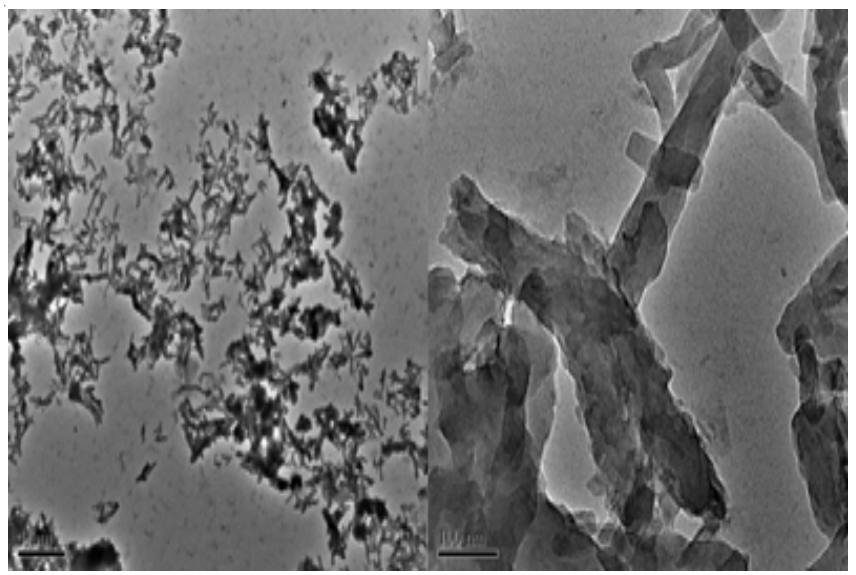

Fig. 2b. HRTEM images of PANI/CeO $\mathrm{C}_{2}$ nanocomposites

exhibit to less surface energy and we found the spherical shape with the size between 10 to 30 from the SEM images.

Ultraviolet studies: The inspirational of electron in molecules and atoms to higher energy state, it is results in absorption of UV-visible light. In all atoms undergoes electron rebel coming after absorption of light. In characteristic of chemical structure, the wavelength of light is absorbed; the molecular species was indentified using by absorption spectrum [16]. UV spectra of PANI/CeO $\mathrm{Ce}_{2}$ nanocomposites in $10 \mathrm{wt} \%$ shows in Fig. 3a. From figure, nanocomposites material showed two absorption at below $400 \mathrm{~nm}$ and one broad absorption above $400 \mathrm{~nm}$. Two absorption bands placed at 324 and $368 \mathrm{~nm}$, other broad bands placed at $858 \mathrm{~nm}$ in the range of UV from charge transition of nanocomposites materials. From figure shows, wavelength fall begin above $1000 \mathrm{~nm}$. The first small peak at $324 \mathrm{~nm}$ is related to the absorption peak of $\mathrm{CeO}_{2}$ nanoparticle [17], which blue shifted from 341 to $324 \mathrm{~nm}$ with decrease due to formation of nanocomposites. The second and third broad absorption peak at 368 and $858 \mathrm{~nm}$ are related to the absorption peak of PANI nanoparticles. The UV absorption sharp peak gives information about band gap. The band gap energy of nanocomposites material have been calculated from the plot (Fig. 3b), these plot drawn between the h $\gamma$ to $(\alpha h \gamma)^{2}$. Here $\gamma$ and $h$ are the normal and usual meaning, $\alpha$ is an absorption coefficient. $\alpha$ is calculated from the relation is $\alpha=2.303$ $\log$ (absorption)/t. where $t$ is a grain size of the nanoparticles. The relation between $\alpha$ and $h \gamma$ is $\alpha h \gamma=\mathrm{A}\left(\mathrm{h} \gamma-\mathrm{E}_{\mathrm{g}}\right)^{1 / 2}$. Where $\mathrm{E}_{\mathrm{g}}$ is a band gap and $\mathrm{A}$ is a constant. The band gap energy have

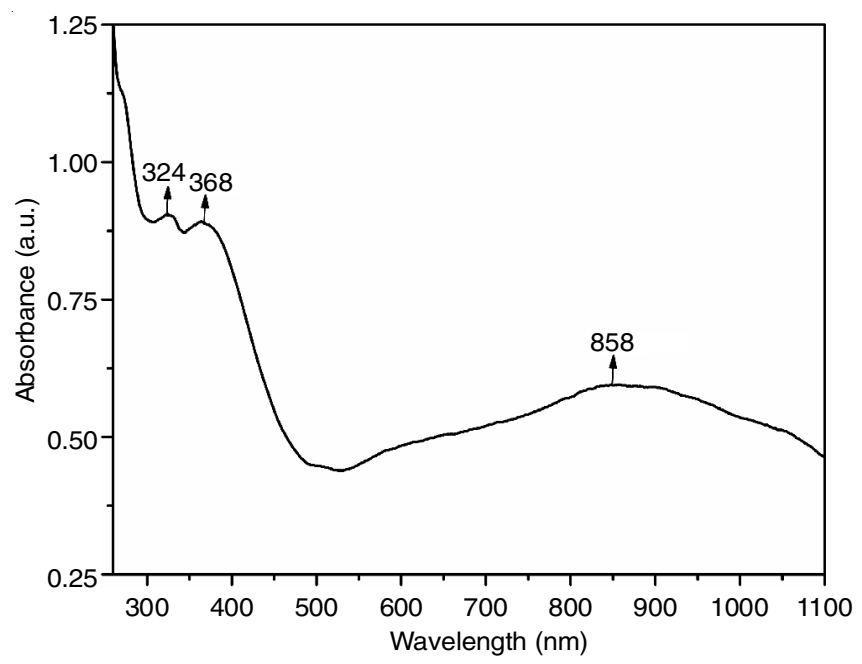

Fig. 3a. UV spectra of $\mathrm{PANI} / \mathrm{CeO}_{2}$ nanocomposites

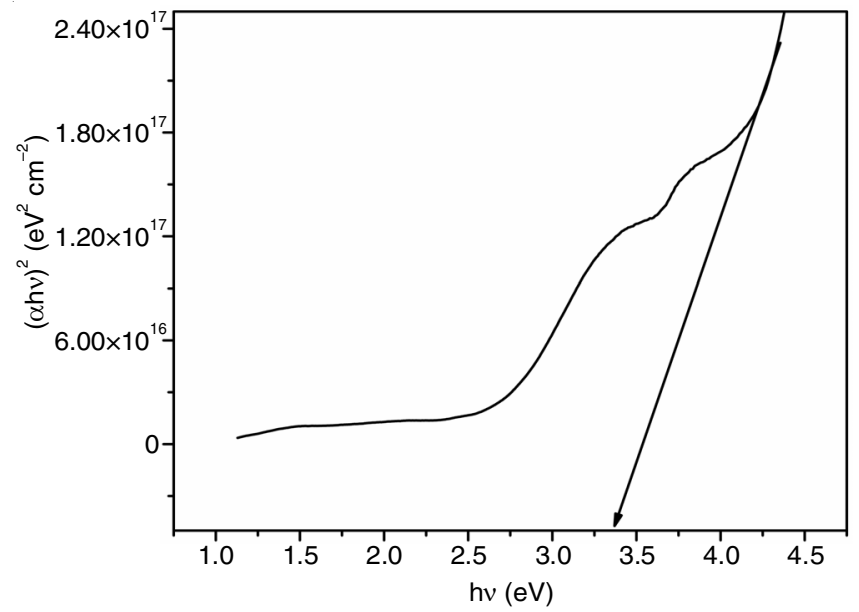

Fig. 3b. Bands gap of $\mathrm{PANI} / \mathrm{CeO}_{2}$ nanocomposites

been obtained which extension of straight line plot of h $\gamma v s$. $(\alpha h \gamma)^{2}, \alpha$ is zero. The band gap energy can be found from the Fig. $3 b$. The band gap energy of $\mathrm{PANI} / \mathrm{CeO}_{2}$ nanocomposite is $3.36 \mathrm{eV}$. It is maximum which have compared to bands gap energy of pure $\mathrm{CuO}_{2}$ and PANI nanoparticls.

FTIR studies: The FTIR spectra shows the execution of the formation of $\mathrm{CeO}_{2}$ and remaining organic part on the surface of $\mathrm{CeO}_{2}$ nanoparticles [18]. Fig. 4 shows the FTIR spectra of $\mathrm{PANI} / \mathrm{CeO}_{2}$ nanocomposites with $10 \mathrm{wt} \%$. From figure, peaks/ bands at $879 \mathrm{~cm}^{-1}$ be associated to metal oxygen bond. The peaks at 1477.37, 1242.07, 702.04 and $507.24 \mathrm{~cm}^{-1}$ agree with the functional groups of PANI. The complex peaks measured at 1658.66 and $1515.94 \mathrm{~cm}^{-1}$ are due to undesirable residues in the nanocomposites. From figure, is measured that there are no peaks linked to residual $\mathrm{H}_{2} \mathrm{O}$ and hydroxyl group of pure $\mathrm{CeO}_{2}$ nanoparticles. The peaks in $1552.59 \mathrm{~cm}^{-1}$ region are assigned to $\mathrm{C}-\mathrm{C}$ stretching mode for benzenoid ring, $1299.93 \mathrm{~cm}^{-1}$ are assigned to $\mathrm{C}-\mathrm{N}$ stretching mode, 1134.07 $\mathrm{cm}^{-1}$ are assigned to $\mathrm{C}=\mathrm{N}$ stretching of secondary aromatic amine, can be requisite the presence of anion serious of acid atoms which are presume to be occupied to counteract the positive ion on the nitrogen molecule of PANI during polymerization. The peaks of wave number $806.19 \mathrm{~cm}^{-1}$ is assigned to aromatic C-H out-of-plane bending [19]. 


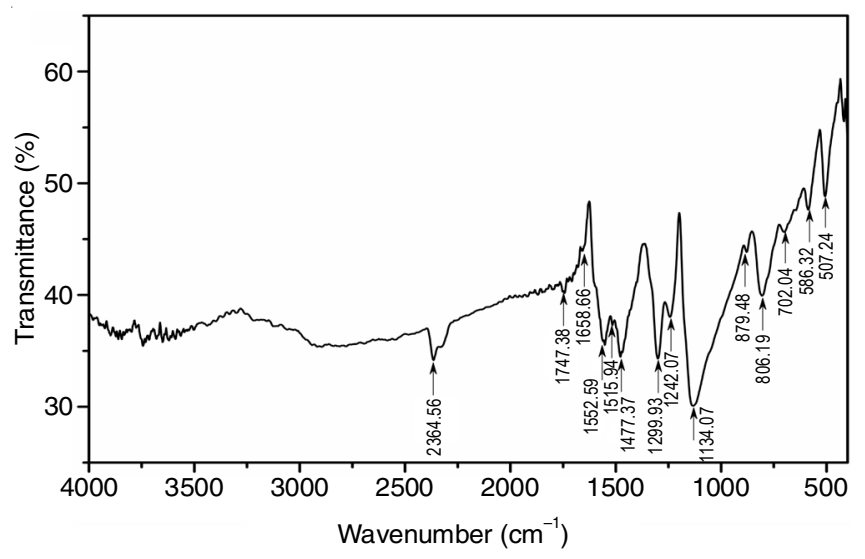

Fig. 4. FTIR spectra of $\mathrm{PANI} / \mathrm{CeO}_{2}$ nanocomposites

AC conductivity studies: Fig. 5 shows the AC conductivity curve of $\mathrm{PANI} / \mathrm{CeO}_{2}$ nanocomposites frequency range from more than $10 \mu \mathrm{Hz}$ to less than $8 \mathrm{MHz}$. Using formula of AC conductivity is

$$
\sigma_{\mathrm{ac}}=\omega \varepsilon_{\mathrm{o}} \varepsilon_{\mathrm{r}},
$$

where $\omega$ is the angular frequency, $\varepsilon_{\mathrm{o}}$ and $\varepsilon_{\mathrm{r}}$ are the permittivity of free space and medium.

The frequency dependence conductivity formula can be written as:

$$
\sigma(\omega)=B(T) \omega(T)^{3}
$$

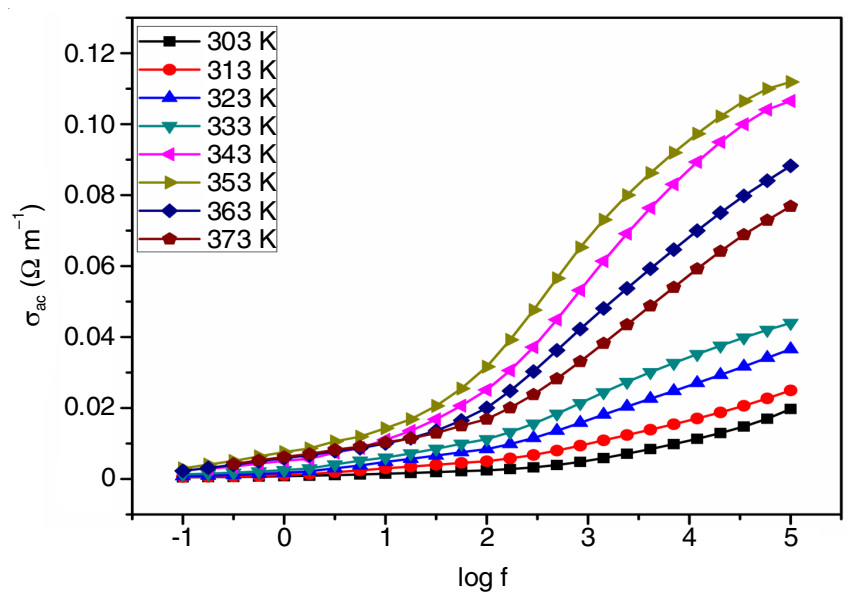

Fig. 5. Conductivity of $\mathrm{PANI} / \mathrm{CeO}_{2}$ nanocomposites

The characteristics of AC conductivity the nanocomposites divulge a frequency independent conductivity in the very low range frequency area [19]. From figure, the high frequency region conductivity increases as the frequency increases [20]. The AC conductivity varied as per variation of frequency and will dependents on the temperature. Upto around $0.5 \mathrm{MHz}$, AC conductivity was continuous constant, more than $0.5 \mathrm{MHz}$, which is measured to be increased as the variation of temperature. Enhance the conductivity of $\mathrm{PANI} / \mathrm{CeO}_{2}$ composites sample on top of pure polyaniline execute happens to be due to the strong assembly of pure $\mathrm{CeO}_{2}$ nanoparticles in the polyaniline matrix and which formation of nanocomposites is good electrical conductivity due to the good electric transport. The frequency dependent conductivity explains that, the charge carrier transferred by doping through the place along polymer chain. The conductivity results are interface charge polarization and intrinsic dipolar polarization [13]. In polymer/ semiconductor composite materials, interfaces of the semiconductor nanoparticles are filled charge carrier and more number of dipole is created. The AC conductivity of $\mathrm{PANI} / \mathrm{CeO}_{2}$ nanocomposites are 0.016, 0.022, 0.036, 0.04, 0.072, 0.09, 0.10 and $0.11 \Omega \mathrm{m}^{-1}$ as the temperature of $303,113,323,333,343$, 353,363 and $373 \mathrm{~K}$, respectively its measured by the frequency of $5 \mathrm{MHz}$.

\section{Conclusion}

in situ Polymerization method has been used for the synthesis of $\mathrm{PANI} / \mathrm{CeO}_{2}$ nanocomposites. The technique is carried out to be efficient for capable to control structural and morphology characteristics. The average grain size of the nanocomposites calculated with help of XRD method and HRTEM image is around $16.5 \mathrm{~nm}$. The collection of nanocomposites samples synthesized is deducted from SEM analysis. The PANI/ $\mathrm{CeO}_{2}$ nanocomposites show a three strong $\mathrm{UV}$ absorption peak at 324,368 and $858 \mathrm{~nm}$, the band gap energy is $3.36 \mathrm{eV}$. The functional group of the nanocomposite materials was analyzed by FTIR spectrum. The frequency dependence AC conductivity was calculated with the help of different temperature region.

\section{ACKNOWLEDGEMENTS}

The authors are thankful to authorities of Tamil Nadu Open University, Saidapet, Chennai and Bharathiyar University, Coimbatore, India for providing necessary research facilities.

\section{CONFLICT OF INTEREST}

The authors declare that there is no conflict of interests regarding the publication of this article.

\section{REFERENCES}

1. A.G. Koniuszewska and J.W. Kaczmar, Prog. Rubber Plast. Recycl. Technol., 32, 1 (2016);

https://doi.org/10.1177/147776061603200101.

2. T. Hanemann and D.V. Szabo, Mater., 3, 3468 (2010); https://doi.org/10.3390/ma3063468.

3. J.S. Duhan, R. Kumar, N. Kumar, P. Kaur, K. Nehra and S. Duhan, Biotechnol. Rep., 15, 11 (2017); https://doi.org/10.1016/j.btre.2017.03.002.

4. D.R. Paul and L.M. Robeson, Polymer, 49, 3187 (2008); https://doi.org/10.1016/j.polymer.2008.04.017.

5. A.L. Porter and J. Youtie, J. Nanopart. Res., 11, 1023 (2009); https://doi.org/10.1007/s11051-009-9607-0.

6. S. Kumar, Int. Res. J. Eng. Technol., 3, 479 (2016).

7. A. Meftah, E. Gharibshahi, N. Soltani, W. Yunus and E. Saion, Polymers, 6, 2435 (2014); https://doi.org/10.3390/polym6092435.

8. R. Balint, N.J. Cassidy and S.H. Cartmell, Acta Biomater, 10, 2341 (2014); https://doi.org/10.1016/j.actbio.2014.02.015.

9. C. Dhand, M. Das, G. Sumana, A.K. Srivastava, M.K. Pandey, C.G. Kim, M. Datta and B.D. Malhotra, Nanoscale, 2, 747 (2010); https://doi.org/10.1039/b9nr00346k.

10. D. Wang, Y. Bao, J.-W. Zha, J. Zhao, Z.-M. Dang and G.-H. Hu, ACS Appl. Mater. Interfaces, 4, 6273 (2012); https://doi.org/10.1021/am3018652.

11. S. Rajeshkumar and P. Naik, Biotechnol. Rep., 17, 1 (2018); https://doi.org/10.1016/j.btre.2017.11.008.

12. G. Jayakumar, A.A. Irudayaraj and A.D. Raj, Mechan. Mater. Sci. Eng., 9, 1 (2017).

13. E. Kumar, S.C. Vella Durai, L.G. Prasad, D. Muthuraj and V.B. Jothy, J. Mater. Environ. Sci., 8, 3490 (2017). 
14. R. Sharma, R. Malik, S. Lamba and S. Annapoorni, Bull. Mater. Sci., 31, 409 (2008); https://doi.org/10.1007/s12034-008-0064-7.

15. E. Kumar, P. Selvarajan and D. Muthuraj, Mater. Res., 16, 269 (2013); https://doi.org/10.1590/S1516-14392013005000021.

16. K.K. Babitha, A. Sreedevi, K.P. Priyanga, B. Sabu and T. Varghese, Indian J. Pure Appl. Phys., 53, 596 (2015).

17. S.S. ammal, V. Shally, M.P. dharshini and G. Jayam, Int. J. Eng. Trends Technol., 49, 69 (2017);

https://doi.org/10.14445/22315381/IJETT-V49P211.
18. S. Vijayalakshmi, Int. J. Eng. Res. Computer Sci. Eng., 5, 750 (2018).

19. B.P. Prasanna, D.N. Avadhani, H.B. Muralidhara, K. Chaitra, V.R. Thomas, M. Revanasiddappa and N. Kathyayini, Bull. Mater. Sci., 39, 667 (2016);

https://doi.org/10.1007/s12034-016-1196-9.

20. D.S. Bai and R.P. Suvarna, Indian J. Sci. Technol., 10, 1 (2017) Fares, Nat. Sci., 3, 1034 (2011);

https://doi.org/10.4236/ns.2011.312129. 